\title{
DIVERSIDADE CULTURAL E INTOLERÂNCIA RELIGIOSA: UMA AFRONTA AOS DIREITOS HUMANOS, UMA QUESTÃO DE EDUCAÇÃO
}

\author{
Marlene Almeida de Ataíde ${ }^{1}$ \\ Jayson Azevedo Marsella de Almeida Pedrosa Vaz Guimarães
}

\begin{abstract}
Resumo: O presente artigo discute sobre a diversidade cultural e a intolerância religiosa produzida na nossa sociedade, não obstante o que prescreve o Artigo XVIII da Declaração Universal dos Direitos Humanos. As questões relativas à diversidade devem ser (re) conhecidas, compreendidas e abordadas no ambiente escolar à luz dos direitos humanos. Nessa perspectiva a educação deveria ser a mola propulsora para a mudança de mentalidades que ainda discrimina o outro nas relações sociais dentre estas a religiosa. Dentro do universo cultural religioso observase que a religiosidade de cada um, bem como sua aceitação por parte dos demais, envolve os interesses políticos de demarcação de território permeados pela dominação ideológica de cada grupo social. Isso interfere muitas vezes não só na identidade cultural, relacionada às raízes históricas de cada povo, como também na subjetividade do sujeito que é vítima da pressão psicológica devido ao preconceito e à intolerância que se manifesta em algumas religiões.
\end{abstract}

Palavras chave: Diversidade cultural; Direitos Humanos; Intolerância; Religião.

\section{CULTURAL DIVERSITY AND RELIGIOUS INTOLERANCE: AN AFFRONT TO HUMAN RIGHTS, AN ISSUE OF EDUCATION}

\begin{abstract}
This article discusses about the cultural diversity and how this still produces in our society the religious intolerance, despite the requirement to Article XVIII of the Universal Declaration of Human Rights. The issues concerning the diversity must be (re) known, understood and dealt with in the school environment in the light of human rights. In this perspective, the education should be the motivation for the change in attitudes that still discriminates against the other in social relations among these the religious. Within the cultural universe religious notes that the religiosity of each one as well as the acceptance of the same by the other involves the political interests of demarcation of territory pervaded by ideological domination of each social group. This affects many times not only in cultural identity, related to historical roots of each people as also in the subjectivity of the subject who is a victim of psychological pressure due to the prejudice and intolerance that is manifested in some religions. Key words: cultural diversity, Human Rights, Intolerance, Religion.
\end{abstract}

Keywords: Cultural diversity; Human rights; Intolerance; Religion.

\footnotetext{
${ }^{1}$ Doutora em Serviço Social pela Pontifícia Universidade Católica de São Paulo - PUC-SP. Docente nos cursos de Graduação em Serviço Social e Pós-Graduação Lato Sensu em Psicologia Social e Terceiro Setor e, Residência Multiprofissional em Saúde da Universidade Santo Amaro (UNISA-SP). Membro da Associação Brasileira de História Oral Líder de pesquisa do Núcleo de Estudos e Pesquisas sobre Diversidade e Serviço Social, credenciada pelo CNPq,

${ }^{2}$ Doutor em Serviço Social pela Pontifícia Universidade Católica de São Paulo-PUC-SP. Docente do Curso de Graduação em Serviço Social pela Universidade Federal do Paraná; tutor da Residência Multiprofissional do Complexo Hospital de Clínica na área profissional Serviço Social; extencionista e pesquisador na área de Direitos Humanos, Cidadania e Saúde; Membro da Associação Brasileira de História Oral.
} 


\section{Introdução}

"Ninguém nasce odiando outra pessoa pela cor de sua pele, por sua origem ou ainda por sua religião. Para odiar, as pessoas precisam aprender; e, se pode aprender a odiar, podem ser ensinadas a amar. (Nelson Mandela)

O Brasil se configura como um país de extenso território, portanto, apresenta variadas diferenças, não somente do ponto de vista climático, como também econômicas, sociais e culturais, de acordo com as respectivas regiões situadas no mapa geográfico brasileiro. No aspecto da sua diversidade cultural que se evidencia por diferentes costumes de uma região para a outra a exemplo das vestes, da culinária, das manifestações religiosas, das tradições, entre outros. Portanto, até as cidades na contemporaneidade estão longe de ser o lugar da homogeneidade cultural, pois são marcadas pelo encontro - e pelo conflito - de diferentes grupos. Tais diferenças podem ser consideradas resultados não apenas das desigualdades sociais, já que encontramos mais diferenças que as divisões entre as classes sociais.

Ao se tratar da cultura brasileira torna-se imprescindível mencionar os colonizadores, a população indígena e africana, seguida pelos imigrantes italianos, japoneses, alemães, poloneses, árabes, entre outros que contribuíram sobremaneira para a pluralidade cultural no nosso país, ou seja, cada um adicionando ao Brasil um novo detalhe cultural, pois o nosso surgimento ocorre da confluência, do entrechoque e do caldeamento do invasor português com índios silvícolas e campineiros e com negros africanos, uns e outros aliciados como escravos (RIBEIRO, 1995).

Não obstante haja uma forte influência que marca a cultura de matriz européia por força da colonização ibérica em nosso país, a cultura considerada como dominante não conseguiu, de todo, apagar as culturas indígenas e africanas. Pelo contrário, o colonizador europeu deixou-se influenciar pela riqueza da pluralidade cultural de índios e negros. No entanto, o modelo de organização implantado pelos portugueses também se fez presente no campo da educação e da cultura.

\footnotetext{
A sociedade e a cultura brasileiras são conformadas como variantes da versão lusitana da tradição civilizatória européia ocidental, diferenciadas por coloridos herdados dos índios americanos e dos negros africanos. O Brasil emerge, assim, como um renovo mutante, remarcado de características próprias, mas atado genesicamente à matriz portuguesa, cujas potencialidades insuspeitadas de ser e de crescer só aqui se realizariam plenamente (RIBEIRO, 1995, p. 20).
} 
Independente desse fato inegável de que somos, em virtude de nossa formação histórico-social, uma nação multirracial e pluriétnica, de notável diversidade cultural, a escola brasileira, no entanto, ainda não aprendeu a conviver com essa realidade e, consequentemente, não trabalha com as crianças e jovens na perspectiva de aceitarem as diversidades étnico-raciais e culturais religiosas entre outros, no espaço escolar, para que esse grupo populacional cresça aceitando e respeitando essa diversidade cultural.

A escola deve ser considerada um espaço formado por uma população com diferentes grupos étnicos, com seus costumes e suas crenças, pois segundo Morin (2001),

[...] a cultura é constituída pelo conjunto dos saberes, fazeres, regras, normas, proibições, estratégias, crenças, idéias, valores, mitos, que se transmite de geração em geração, se reproduz em cada indivíduo, controla a existência da sociedade e mantém a complexidade psicológica e social. Não sociedade humana, arcaica ou moderna, desprovida de cultura, mas cada cultura é singular. Assim, sempre existe a cultura nas culturas, mas a cultura existe apenas por meio das culturas (MORIN, 2001, p. 56).

Dessa forma, somente muito recente, e, por pressão dos movimentos sociais, a questão da pluralidade cultural vem encontrando certa repercussão no ambiente escolar, e que, segundo a análise de Gadotti (1992),

[...] a diversidade cultural é a riqueza da humanidade. Para cumprir sua tarefa humanista, a escola precisa mostrar aos alunos que existem outras culturas além da sua. Por isso, a escola tem que ser local como ponto de partida, mas tem que ser internacional e intercultural como ponto de chegada. [...] Escola autônoma significa escola curiosa, ousada, buscando dialogar com todas as culturas e concepções de mundo. Pluralismo não significa ecletismo, um conjunto amorfo de retalhos culturais (GADOTTI, 1992, p. 23).

Isso significa a real importância, sobretudo do diálogo com todas as culturas, a partir de uma cultura que se abre às demais. Consideramos, portanto, que há ainda um longo caminho que necessita ser percorrido para que a escola seja, de fato, um instrumento de afirmação de uma identidade pluricultural.

Ressalta-se, por oportuno que, no mês de novembro de 2001, a Organização das Nações Unidas para a Educação, a Ciência e a Cultura - UNESCO proclamou a Declaração Universal sobre a diversidade cultural, e a reconhece seu Artigo 1, como "herança comum da humanidade", ao considerar como um imperativo concreto e ético inseparável do respeito à dignidade humana. Logo após, a Assembléia Geral da ONU proclamou o dia 21 de maio como o Dia Mundial da Diversidade Cultural para o Diálogo e o Desenvolvimento, o qual tem como finalidade conscientizar a população sobre a riqueza das diversas culturas do mundo e aprofundar a reflexão sobre as 
oportunidades que a diversidade cultural pode trazer às sociedades (UNESCO, 2001, s/p.).

Nessa perspectiva, a Declaração Universal dos Direitos Humanos no seu Art. XVIII frisa que,

Toda pessoa tem o direito à liberdade de pensamento, consciência e religião; este direito inclui a liberdade de mudar de religião ou crença e a liberdade de manifestar essa religião ou crença, pelo ensino, pela prática, pelo culto e pela observância, isolada ou coletivamente, em público ou em particular.

A nossa Carta Cidadã de 1988, defende no seu artigo 5, inciso VI, que "[...] É inviolável a liberdade de consciência e de crença, sendo assegurado o livre exercício dos cultos religiosos e garantida, na forma da lei, a proteção aos locais de culto e suas liturgias". Por outro lado, o Programa Nacional dos Direitos Humanos, no que diz respeito à crença e culto $(2010$, p. 273$)$ na sua proposta 110 asseveram de forma contundente a seguinte questão: “[...] Prevenir e combater a intolerância religiosa, inclusive no que diz respeito a religiões minoritárias e a cultos afro-brasileiros". Por fim, o Programa Nacional dos Direitos Humanos (2010, p. 273) na sua propositura 113, legisla no sentido de "[...] Incentivar o diálogo entre movimentos religiosos sob o prisma da construção de uma sociedade pluralista, com base no reconhecimento e no respeito às diferenças de crença e culto”.

\title{
Diversidade cultural e religiosidade: respeito às diferenças
}

"Temos o direito de ser iguais sempre que as diferenças nos inferiorizem, temos o direito de ser diferentes sempre que a igualdade nos descaracterize".

(Boaventura de Souza Santos)

\begin{abstract}
A beleza do nosso país reside justamente na diversidade cultural e religiosa de seu povo. (...) Temos que quebrar as barreiras que nos impedem de dialogar com aqueles e aquelas que pensam e que agem de forma diferente, mas que têm o mesmo objetivo: a valorização da VIDA! (Mahatma Gandhi)
\end{abstract}

Preliminarmente é importante realizar uma visita à literatura para conhecer autores que discutem a categoria cultura do ponto de vista antropológico. No decorrer da referida visita, encontramos Franz Boas (2004), considerado um dos precursores. O 
referido antropólogo afirma que toda cultura tem uma história própria que se desenvolve de forma particular e não pode ser julgada a partir da história de outras culturas. Desde o início do século XX, Boas usou a História para explicar a diversidade cultural e a grande diferença de culturas na humanidade, com isso faz pela primeira vez uma aproximação entre História e Antropologia até hoje bastante utilizada que exerceu influências em obras como "Casa-grande e Senzala”, de Gilberto Freyre (2006), adepto de Franz Boas.

Importante ressaltar que não há na Antropologia atual um consenso entre os autores para se definir o que é cultura, tendo em vista que são conceitos destoantes de acordo com a visão do antropólogo. Todavia, há acordos em relação a alguns pontos dessas várias definições, pois em alguns pontos se colocam as diferenças genéticas que não determinam comportamentos culturais, ou seja, toda divisão de trabalho com base no gênero ou na raça, apenas para ilustrar, é cultural e não predeterminada pela natureza. Essa mesma premissa colabora na afirmação de que o meio geográfico por seu turno não caracteriza comportamentos culturais. Nessa direção pode-se inferir que quaisquer tipos de discriminações sociais feitas com base em gênero ou raça, como aquelas manifestações postas em nossa sociedade ao reproduzir que determinados trabalhos não podem ser executados por mulheres ou que algumas atividades consideradas inferiores são exclusivamente "trabalho de negro" não possuem base biológica. Mas são discursos gerados para provar a posição dominante de determinados grupos sociais.

No entanto, nem toda definição de cultura vem da Antropologia. No nosso país temos o intelectual Alfredo Bosi (1992), por exemplo, que em sua obra intitulada "Dialética da colonização", define cultura a partir da linguística e da etimologia da palavra: cultura, assim como culto e colonização, viria do verbo latino colo, que significa eи осиро a terra. Cultura, dessa forma, seria o futuro de tal verbo, significando o que se vai trabalhar, o que se quer cultivar, e não apenas em termos de agricultura, mas também de transmissão de valores e conhecimento para as próximas gerações.

Nesse sentido, Bosi (1992) afirma que cultura é o conjunto de práticas, de técnicas, de símbolos e de valores que devem ser transmitidos às novas gerações para garantir a convivência social. Mas para haver cultura é preciso antes que exista também uma consciência coletiva que, a partir da vida cotidiana, elabore os planos para o futuro da comunidade. Tal definição dá à cultura um significado muito próximo do ato de 
educar. Assim sendo, nessa perspectiva, cultura seria aquilo que um povo ensina aos seus descendentes para garantir sua sobrevivência.

Moreira (2007), em seus estudos culturais, entende a palavra "cultura" no sentido plural como "culturas" ao afirmar que,

[...] corresponde aos diversos modos de vida, valores e significados compartilhados por diferentes grupos (nações, classes sociais, grupos étnicos, culturas regionais, geracionais, de gênero etc.) e períodos históricos. Trata-se de uma visão antropológica de cultura, em que se enfatizam os significados que os grupos compartilham, ou seja, os conteúdos culturais. Cultura identifica-se, assim, com a forma geral devida de um dado grupo social, com as representações da realidade e as visões de mundo adotadas por esse grupo (MOREIRA, 2007, p. 17).

Do ponto de vista sociológico, a cultura nasce a partir da interação entre os homens. Nessa perspectiva, a cultura brasileira, como qualquer tipo de cultura é pluricultural. Ou seja, é envolvida por diversas culturas, respeitando as diferenças apresentadas pelas mesmas. No caso da sociedade brasileira, está formada não só por diferentes etnias, como também por imigrantes de diferentes países. Além disso, as migrações colocam em contato grupos bastante diversos e que a convivência entre esses grupos nos planos cultural e social é marcada pelo preconceito e pela discriminação.

Há, na nossa sociedade, uma variedade de identidades culturais que, para Langon (2003), representa a riqueza de caminhos diversos para enfrentar, de modos distintos, desafios também parcialmente diferentes:

O desaparecimento dessa diversidade significaria o desaparecimento da capacidade humana de dar respostas variadas ao novo; seria a ruptura de uma das condições de possibilidade de reprodução da vida humana. O desaparecimento de uma dessas identidades culturais representa o empobrecimento da humanidade enquanto fecha um dos caminhos abertos, enquanto faz perder uma das possibilidades. A riqueza humana depende da preservação da diversidade de suas identidades culturais e de cada identidade cultural (LANGON, 2003, p. 79).

Para a UNESCO (2001) a diversidade cultural cria um mundo rico e variado. Esse mundo aumenta a gama de possibilidades de escolhas que se oferecem a todos. Nutre as capacidades e valores humanos, constituindo um dos principais promotores do desenvolvimento, entendido não somente em termos econômicos, mas também como meio de acesso a uma existência intelectual, afetiva, moral e espiritual satisfatória. É, para o gênero humano, tão necessário como a diversidade biológica para a natureza. Constitui patrimônio comum da humanidade e deve ser reconhecida e consolidada em benefício das gerações presentes e futuras. Por isso em sociedades cada vez mais 
diversificadas torna-se indispensável garantir uma interação harmoniosa entre sujeitos e grupos com identidades culturais distintas.

\begin{abstract}
'Diversidade cultural' refere-se à multiplicidade de formas pelas quais as culturas dos grupos e sociedades encontram sua expressão. Tais expressões são transmitidas entre e dentro dos grupos e sociedades. A diversidade cultural se manifesta não apenas nas variadas formas pelas quais se expressa, se enriquece e se transmite o patrimônio cultural da humanidade mediante a variedade das expressões culturais, mas também através dos diversos modos de criação, produção, difusão, distribuição e fruição das expressões culturais, quaisquer que sejam os meios e tecnologias empregados. (UNESCO, 2001).
\end{abstract}

Em concordância com a UNESCO, infere-se que a diversidade cultural é fonte de desenvolvimento mútuo das diversas culturas em interação, bem como de toda a humanidade. É uma riqueza mesmo quando exige esforços para convivência entre culturas diversas, divergentes e opostas, possibilitando que cada sujeito ou grupo, através do esforço de compreensão das outras culturas, aprenda a se relacionar de maneira positiva com as diferenças.

Nessa direção, integram o universo cultural de inúmeros grupos sociais conjuntos de manifestações, expressões, crenças, movimentos e tradições de cunho religioso. Essa rica diversidade religiosa tem despertado e ocupado, historicamente, esforços de diversas ciências que buscam compreender e interpretar a presença do religioso no campo social.

Mas, a palavra diversidade, segundo Geertz (2001, p. 76), deve ser encarada sob uma perspectiva de continuidade, ou seja, ('entre mim e os que pensam diferente de mim'), como algo que nos possibilita a transformação no modo de vermos a nós mesmos. Portanto, a diversidade é uma categoria de análise que vem se destacando nos debates da atualidade. Aspectos como racismo, preconceito, discriminação e intolerância religiosa têm sido preocupações relevantes nas reflexões que vêm sendo levantadas nos meios acadêmicos e fora deles (família, trabalho e mídia).

Do ponto de vista da diversidade religiosa, diferentes religiosidades, crenças, movimentos, filosofias, religiões, dentre outras, contribuem e, por vezes, determinam os modos de como o ser humano se posiciona no mundo, orientando o relacionamento com seus semelhantes e com a natureza, constituindo referências para a constituição das identidades culturais.

Vale acrescentar que quando nos referimos à diversidade religiosa, a escola foi em um primeiro momento instrumento fundamental do catolicismo no projeto 
civilizatório-colonizador, quando se difundiam por meia dela os preceitos tidos como únicos e universais. Nessa tentativa, o currículo e a organização do cotidiano escolar, visavam tão somente catequizar os sujeitos, enfocando uma verdade padronizadora que negava quaisquer outras formas de religiosidades/tradições religiosas.

Não obstante, torna-se oportuno frisar que vivemos numa sociedade plural, e, nessa perspectiva, essa mesma sociedade deve ser vista sob uma perspectiva laica, se considerarmos que o Estado brasileiro é laico, mas por outro lado,

O conceito da laicidade, embora em linhas gerais seja simples, [...] é pleno de consequências. [...] as mais importantes e evidentes dessas consequências relacionam-se à criação de um espaço público livre, em que é possível a todos os cidadãos pensarem mais ou menos o que quiserem, assim como exporem mais ou menos todas as suas opiniões sem constrangimentos e poderem organizar-se para compartilhar, celebrar, promover e implementar suas ideias. Assim como o Estado não pode beneficiar crenças na forma de doutrinas oficiais de Estado, as Igrejas e os grupos filosóficos (ou 'ideológicos') estão vetados de lançarem mão do Estado para conseguirem adeptos e privilégios (LACERDA, 2014, p. 199).

Isso significa que ele não deve ter religião. Mas tem o dever de garantir a liberdade religiosa. No Artigo $5^{\circ}$, inciso VI, da Constituição Federal de 1988, consta que: "É inviolável a liberdade de consciência e de crença, sendo assegurado o livre exercício dos cultos religiosos e garantida, na forma da lei, a proteção aos locais de culto e as suas liturgias." Portanto, a liberdade religiosa é um dos direitos fundamentais da humanidade, como afirma a Declaração Universal dos Direitos Humanos, da qual somos signatários.

Além das legislações mencionadas temos a Lei de Diretrizes e Bases da Educação - LDB, que foi incorporada no âmbito dos Parâmetros Curriculares Nacionais - PCNs em que está regulamentada a garantia em relação ao oferecimento do ensino religioso, em que cabe aos estados e municípios optar pelo ensino confessional ou interconfessional,

Art. $\mathbf{3 3}^{\mathbf{0}}$. O ensino religioso, de matrícula facultativa, constitui disciplina dos horários normais das escolas públicas de ensino fundamental, sendo oferecido, sem ônus para os cofres públicos, de acordo com as preferências manifestadas pelos alunos ou por seus responsáveis, em caráter:

I - confessional, de acordo com a opção religiosa do aluno ou do seu responsável, ministrado por professores ou orientadores religiosos preparados e credenciados pelas respectivas igrejas ou entidades religiosas; ou

II - interconfessional, resultante de acordo entre as diversas entidades religiosas, que se responsabilizarão pela elaboração do respectivo programa. 
"As religiões, portanto, fazem parte da cultura humana, presentes em todos os povos, em todas as épocas históricas. Nesse sentido, embora diferentes, todas têm algo em comum: a busca de uma relação com o mundo metafísico". (SILVEIRA; OLIVEIRA; KOCH; et.al., s/d, p. 3).

Por outro lado, no nosso cotidiano observa-se certa indiferença frente à diversidade religiosa presente em nosso contexto brasileiro. Dessa forma, a intolerância religiosa é hoje analisada, como um dos temas mais difíceis de serem enfrentados pelos docentes, pelas escolas e pelo espaço universitário, cuja falta de tolerância infringe a dignidade da pessoa humana, protegida pela Declaração Universal dos Direitos Humanos conforme mencionado anteriormente.

Ao longo da história, infelizmente, a convivência dos seres humanos, dos grupos sociais, das várias sociedades, com outros seres humanos, ou seja, com o Outro, nem sempre foi pacífica. A intolerância se expressa diante de várias diversidades: de gênero, de etnia, de geração, de orientação sexual, de padrão físico-estético, e, também, de religião/religiosidade. (SILVEIRA; OLIVEIRA; KOCH; et.al., s/d, p. 5).

Dessa forma, sublinhando o já mencionado anteriormente o "Programa Nacional dos Direitos Humanos pretende incentivar o diálogo entre os movimentos religiosos, para a construção de uma sociedade verdadeiramente pluralista, com base no reconhecimento e no respeito às diferenças". (BRASIL. SECRETARIA DE DIREITOS HUMANOS, 2004, p. 6)

Nesse sentido torna-se importante corroborar com Gabatz (2012, p. 53), ao asseverar que,

É preciso lembrar sempre que a intolerância religiosa se expressa em pequenos conflitos cotidianos, quando se desqualifica pessoas por não pensarem do mesmo modo de quem as desqualifica; ou quando se destroem locais de culto ou símbolos de religiões consideradas adversárias, inimigas, incorretas. Pior ainda quando o indivíduo se arroga o direito de qualificar a crença alheia de forma depreciativa se valendo de uma terminologia autoritária, como por exemplo, seita, pagão, não cristão, sem Deus (GABATZ, 2012, p. 53).

Ressalta-se que sempre houve uma crença acerca da escola considerada como um espaço de formação onde se constrói o conhecimento e, ainda, o lócus de socialização dos conhecimentos historicamente produzidos e acumulados. Portanto essa instituição na forma em que foi concebida deveria ter como dever primordial assumir a tarefa de educar, além de colocar o conhecimento religioso à disposição de todos os que desejam acessá-lo. 
De acordo com a Lei no 9.394/1996 - Lei de Diretrizes e Bases da Educação Nacional - a educação é definida em seu artigo $1^{\circ}$, da seguinte forma: "A educação abrange os processos formativos que desenvolvem na vida familiar, na convivência humana, no trabalho, nas instituições de ensino e pesquisa, nos movimentos sociais e organizações da sociedade civil e nas manifestações culturais".

Isto porque o homem é um ser social e, portanto, possui sua individualidade e diversidade. No seu convívio social, adquire novas características, novos hábitos, atitudes, valores culturais. E, para sentir-se bem, precisa estar bem consigo mesmo e com os diferentes grupos sociais que conviva e, com isso, o homem vai adquirindo habilidades diversas, completando-se e completando a sociedade

Infere-se ainda, que o poder da religião na educação e no comportamento dos indivíduos manifesta-se através da imposição de uma cultura sobre outra. Todos nós somos responsáveis para que no processo cultural as crenças religiosas, assim como os demais aspectos do processo multicultural, se espalhem pelo mundo como verdades universais. Ou seja, o que pregam deve ser seguido pelos seus membros, sendo assim, respeitadas e difundidas entre aqueles que consideram a religião como parte fundamental para o seu desenvolvimento humano, enquanto ser social.

A diversidade e a pluralidade cultural no Brasil apresentam-se com grande riqueza, pois temos manifestações de diversos povos com culturas diferentes tornando nosso conhecimento um valor imenso, ou seja, essa herança cultural será usada como recurso para a melhoria de vida de nossa população atual e futura por isso deve ser preservada para que as demais gerações se apropriem de todo esse conhecimento que foi adquirido por meio dos milênios por todos esses povos.

As influências européias, asiáticas e indígenas em todas as áreas do conhecimento têm para cada um com seu valor inestimável. Cabe a cada cidadão dar o valor necessário a todas elas, tanto na arte, quanto nas ciências, medicina, culinárias, línguas, etc., ensinando as nossas crianças sobre a riqueza do nosso patrimônio cultural brasileiro. Assim, para viver democraticamente em uma sociedade multicultural é preciso conhecer e respeitar as diferentes culturas que a constituem. E o ambiente escolar é o espaço privilegiado para promover o conhecimento e a valorização da trajetória dos diferentes grupos sociais, pois só assim será possível superar atitudes de intolerância em relação às diferenças culturais e religiosidades. 
Ao tratar da questão da pluralidade cultural nos seus fundamentos éticos, os Parâmetros Curriculares Nacionais - PCN afirmam que:

A contribuição da escola na construção da democracia é a de promover os princípios éticos de liberdade, dignidade, respeito mútuo, justiça e eqüidade, solidariedade, diálogo no cotidiano; é a de encontrar formas de cumprir o princípio constitucional de igualdade, o que exige sensibilidade para a questão da diversidade cultural e ações decididas em relação aos problemas gerados pela injustiça social. (BRASIL. SECRETARIA DE EDUCAÇÃO FUNDAMENTAL, 1997, p. 129).

De acordo com a pesquisa realizada por Abramo (2005, p. 265) os jovens que foram entrevistados sinalizaram para a multiplicação de igrejas e grupos de várias tradições religiosas. Para eles também surgem possibilidades de combinar elementos de diferentes espiritualidades em uma síntese: “pessoal e intransferível”. Ou seja: “[...] nos dias atuais, aparece constantemente novas possibilidades sincréticas que, ao mesmo tempo (re)produzem identidades institucionais e até novos fundamentalismos". Diante da perspectiva apresentada pela pesquisa da referida autora, no que diz respeito ao perfil da juventude brasileira, é inconcebível descuidar sobre a importância de abertura de espaços para que possamos conhecer, discutir, narrar e refletir nas escolas e em outros espaços acadêmicos a respeito das diversificadas matrizes de religiões e religiosidades presentes não somente na vida dos jovens do nosso país, mas também de adultos que frequentam espaços acadêmicos como Universidades e Faculdades, que em alguns momentos tendem a isolar ou excluir aqueles que professam alguma religião que não faz parte do seu universo.

No campo educacional, difundem suas crenças em escolas próprias e em escolas públicas, mediante disciplinas do currículo nas quais desenvolvem atividades que afrontam os conteúdos das demais. E formam elites dirigentes em universidades e faculdades confessionais, com diplomas reconhecidos pelo Estado e pelo mercado. (CUNHA e OLIVA, 2014, p. 208).

Se partirmos de uma perspectiva plural, o panorama religioso deve ser apresentado em sua multiplicidade para que possa proporcionar o compartilhar de experiências e a riqueza de suas simbologias, o que evidencia as diversas faces do sagrado presente em nossa sociedade. Portanto, se faz premente pensar a disciplina de Ensino Religioso como um espaço para a conversação no que diz respeito à diversidade cultural religiosa. Tal conversação deve na sua essência tratar da convivência, do entendimento, do diálogo, do investigar o próprio pensamento e o do outro por intermédio do ato ou efeito de conversar. E, nesse contexto, podemos abrir espaços para conhecer, discutir, narrar e refletir nas escolas acerca das diferentes religiões e 
religiosidades presentes na vida dos jovens e adultos do nosso país, pois se trata de um tema que carece atenção nas escolas por parte de todos os atores envolvidos no processo educativo, mas principalmente pelos educadores que ministram a disciplina de Ensino Religioso que podem encontrar na exposição das aulas os meios que provoquem reflexões e ações transformadoras no quadro da intolerância religiosa (mesmo que de forma velada) que se apresenta na contemporaneidade. Segundo Silva e Ribeiro (2007, p. 13):

Um dos grandes desafios para a convivência social é encontrar maneiras de diálogo com o diferente. Por muito tempo se procurou encontrar o que os grupos têm em comum. No entanto, descobriu-se que além de ter algo em comum, se faz necessário que a convivência se dê também pela diferença.

Nesse sentido, devemos ressaltar que a aceitação do outro, do diferente, é um importante aprendizado e exercício de convívio social que precisa ter como base o respeito, por aquilo que encontramos de comum nas diferentes religiões e pelo que nos causa estranhamento, pois "tradição e cultura não podem servir de pretextos para restringir convicções e suas manifestações legítimas" (SILVA e RIBEIRO, 2007, p. 31).

\section{Considerações finais: sem finalizar}

"O diálogo se dá entre iguais e diferentes, nunca entre antagônicos.”

(Moacir Gadotti)

"É impossível estabelecer um diálogo racional com alguém a respeito de crenças e conceitos que não foram adquiridos por meio da razão". (Carlos Ruiz Zafón)

O não reconhecimento da diversidade religiosa e a naturalização de preconceitos de caráter religioso evidenciam a necessidade de que o currículo escolar seja oficial ou oculto/real, se desprender da perspectiva monocultural/confessional. Isso consiste enquanto um desafio para a alteração de ritos, ritmos e processos educativos que desprestigiam o conhecimento religioso historicamente produzido pela humanidade, bem como colaboram para a manutenção de rótulos e estereótipos em relação a determinadas identidades religiosas.

Conhecer, valorizar e respeitar a diversidade religiosa, como patrimônio da humanidade, significa reconhecer que cada cultura tem, em sua estruturação e 
manutenção, um substrato religioso que fundamenta crenças, comportamentos, atitudes, valores, símbolos e referenciais. Isso requer a construção de currículos que abarquem a complexidade das culturas e das relações humanas, integrando a diversidade de lógicas, conceitos e sujeitos, a fim de questionar paradigmas que legitimam processos de exclusão e desigualdade.

Alguns dos grandes desafios que se impõem aos currículos escolares na atualidade brasileira são romper conceitos cristalizados e práticas estigmatizadoras; reconhecer a diversidade cultural religiosa, abrindo possibilidades para diálogos, encontros e relações com o outro; e sensibilizar educadores e educandos diante de qualquer discriminação étnico-cultural ou religiosa. (CECCHETTI; OLIVEIRA, 2009).

Reconhecer o "religioso" em sua diversidade, ao invés de excluí-lo da escola ou aprisioná-lo sob os imperativos de uma cultura do confessionalismo, implica mudar não apenas as intenções do que se quer transmitir, mas os processos internos que são desenvolvidos. Essa mudança necessária perpassa a utilização de outra base epistemológica, de perspectiva intercultural, bem como a adoção de outros métodos pedagógicos, o desenvolvimento de outra formação docente, que abarque a complexidade das culturas e das relações humanas. Não reconhecer a diversidade, não incorporá-la como elemento de aprendizagem, são limitações teórico-metodológicas com as quais alguns legisladores, pesquisadores, educadores e gestores demonstram não estarem sensíveis à heterogeneidade, à diversidade de culturas que compõe as sociedades.

Enquanto lugar de trânsito de culturas, de encontro, de relações com múltiplas diversidades, cabe à escola, socializar o conhecimento historicamente produzido pela humanidade, entre eles, o religioso, com sua riqueza de identidades, linguagens, símbolos e valores, garantindo a liberdade religiosa dos cidadãos, disponibilizando saberes e práticas de todas as culturas, tradições/grupos religiosos e não-religiosos, pois,

Uma educação comprometida com a diversidade de seus sujeitos e situações requer de toda a sociedade e, particularmente da comunidade escolar, um conjunto de reflexões e práticas, que abordem as diferenças dentro e além dos seus espaços e lugares. A diversidade cultural religiosa se apresenta e transita, de forma marcante, nas salas de aula das escolas brasileiras, espaços e lugares sociais que possibilitam, ou não, o encontro de diferentes sujeitos, cada qual com seus símbolos, ritos, crenças, tempos, culturas e valores próprios. (SILVEIRA; OLIVEIRA; KOCH; et. al., s/d, p. 8-9) 
O diálogo deve ser o mais importante instrumento para a comunicação, que proporcionará ao aluno as oportunidades de ter as diferentes formas de ver e pensar o mundo em que vive, para que tenha condições de se pronunciar concordando ou discordando e criticando com sugestões, se necessário, para que assim possa ter verdadeira prática cidadã e transformar a sociedade num espaço mais respeitoso e voltado ao trabalho com as diferenças.

Do ponto de vista comparativo a outros países, o campo religioso é, no Brasil, extremamente complexo, pois abarca religiões com diferentes graus de institucionalização e de distintas tradições culturais. Encontramos no país desde o monoteísmo judaico-cristão até o politeísmo indígena ou de origem africana e as mais recentes incorporações de tradições orientais, inclusive de religiões que não possuem a noção de Deus (CUNHA e OLIVA, 2014).

\section{Referências}

ABRAMO, Helena W. e BRANCO, Pedro Paulo M. (Orgs). Retratos da juventude brasileira: análises de uma pesquisa social. São Paulo: Fundação Perseu Abramo e Instituto Cidadania, 2005.

BOAS, Franz. Antropologia cultural. Textos selecionados, apresentação e tradução, Celso Castro. Rio de Janeiro-RJ: Jorge Zahar Editor Ltda, 2004.

BOSI, Alfredo. Dialética da colonização. São Paulo: Companhia das Letras, 1992.

BRASIL. CONSTITUIÇÃO DA REPÍBLICA FEDERATIVA DO BRASIL, 1988. SECRETARIA DE EDUCAÇÃO FUNDAMENTAL. Parâmetros

curriculares nacionais: introdução aos parâmetros curriculares nacionais / Secretaria de Educação Fundamental. - Brasília: MEC/SEF, 1997. 126p. . SECRETARIA ESPECIAL DOS DIREITOS HUMANOS. Diversidade religiosa e direitos humanos. Brasília: 2004.

CECCHETTI, Elcio; OLIVEIRA, Lilian Blanck. Diversidade cultural e cultura da escola: desafios e perspectivas para as DCNs de formação docente em Ensino Religioso. In: Anais III Simpósio Internacional sobre Religiosidades, Diálogos Culturais e Hibridações. Campo Grande/MS: Universidade Federal de Mato Grosso do Sul/UFMS, 2009.

COSTA, Jurandir Freire. Disponível em:

https://www.pensador.com/autor/jurandir_freire_costa/ Acesso em 12/jul./2017.

CUNHA, Luiz Antônio Cunha; OLIVA, Carlos Eduardo Oliva. Sete Teses Equivocadas sobre o Estado Laico. In: Conselho Nacional do Ministério Público. Brasília: CNMP, 2014. 300 p. il. v. 1. 
FREYRE, Gilberto. Casa Grande \& senzala: formação da família brasileira sob o regime da economia patriarcal. São Paulo: Global, 2006.

GABATZ, Celso. Diversidade cultural e religiosa e os desafios para uma educação inclusiva. In: Anais do Congresso Internacional das Faculdades EST. São Leopoldo: EST, v. 1, 2012, p. 50-63

GADOTTI, Moacir. Diversidade cultural e educação para todos. Rio de Janeiro: Graal, 1992.

FREIRE, Paulo; GUIMARÃES, Sergio. Pedagogia: diálogo e conflito. São Paulo: Cortez, 1995.

GANDHI, Mahatma. Disponível em:

https://www.pensador.com/mahatma_gandhi_frases_de_religiao/ Acesso em 12/mai./2017.

GEERTZ, Clifford. Anti anti-relativismo, In: Nova luz sobre a antropologia. Rio de Janeiro, Jorge Zahar, 2001.

LACERDA, Gustavo Biscaia de. Sobre as relações entre Igreja e Estado: conceituando a laicidade. In: Conselho Nacional do Ministério Público. Brasília: CNMP, 2014. 300 p. il. v. 1.

LANGON, Maurício. Diversidade cultural e pobreza. In: SIDEKUM, Antônio (org.). Alteridade e multiculturalismo. Ijuí: Ed. Unijuí, 2003.

LEI DE DIRETRIZES E BASES DA EDUCAÇÃO NACIONAL. Lei nº 9.394, de 20 de dezembro de 1996. Disponível em:

http://www.planalto.gov.br/ccivil_03/leis/19394.htm Acesso em: 19/mai./2015.

MANDELA, Nelson. Epígrafe. In: Diversidade religiosa e Direitos Humanos. Secretaria de Direitos Humanos da Presidência da República. 2013. Disponível em:

http://www.sdh.gov.br/assuntos/bibliotecavirtual/promocao-e-defesa/publicacoes-

2013/pdfs/diversidade-religiosa-e-direitos-humanos Acesso em: 08/jul./2017.

MOREIRA, Antonio Flávio Barbosa. Currículo, conhecimento e cultura In: MEC -

Indagações sobre Currículo. Brasília, Ministério da Educação: Secretaria de Educação Básica: 2007.

MORIN, Edgar. Os sete saberes necessários à educação do futuro. São Paulo: Cortez, 2001.

RIBEIRO, Darci. O povo brasileiro: a formação e o sentido do Brasil. São Paulo: Cia das Letras, 1995.

SANTOS, Boaventura de Sousa (Org.). Reconhecer para libertar: os caminhos do cosmopolitismo multicultural. Rio de Janeiro: Civilização Brasileira, 2003.

SILVA, Clemildo A. RIBEIRO, Mario B. Intolerância religiosa e direitos humanos. Porto Alegre, Editora Sulina, Editora Universitária Metodista, 2007.

SILVEIRA, Rosa Maria Godoy; OLIVEIRA, Lilian Blanck de; Simone Risck-KOCH; CECCHETTI, Elcio. Diversidade religiosa e direitos humanos. Disponível em: http://www.mpgo.mp.br/portal/system/resources/W1siZiIsIjIwMTMvMDQvMjUvMDlf MjBfMTdfMzEzX0RpdmVyc2lkYWRIX3JlbGlnaW9zYV91X2RpcmVpdG9zX2h1bW Fub3MucGRmIl1d/Diversidade\%20religiosa\%20e\%20direitos\%20humanos.pdf Acesso em 15/jun./2015. 
UNESCO. Organização das Nações Unidas para Educação, a Ciência e a Cultura. Declaração Universal sobre a Diversidade Cultural. $31^{\text {a }}$ Sessão da Conferência Geral. Paris, 2001. Disponível em http:

http://unesdoc.unesco.org/images/0012/001271/127160por.pdf. Acesso em 06 mai. 2017.

ZAFÓN, Carlos Ruiz. Disponível em: http://poetizando.com.br/frase/carlos-ruizzafon/4970b4e85d1d4d7090e18345a286a5ec Acesso em 08/jul./2017. 